\title{
RICE AREA INTERANNUAL VARIATION THROUGH A REMOTE SENSING BASED MAPPING ALGORITHM
}

\author{
A. M. Elshorbagy ${ }^{\mathrm{a}, *}$, E. Imam $^{\mathrm{a}}$, M. Nour ${ }^{\mathrm{b}}$ \\ ${ }^{a}$ School of Sciences and Engineering, Environmental Engineering, The American University in Cairo, New Cairo \\ 11835,Egypt - (elshorbagy, eimam, mnour)@aucegypt.edu \\ ${ }^{\mathrm{b}}$ Irrigation and Hydraulics Department, Faculty of Engineering, Cairo University, Orman, Giza, Egypt
}

\author{
Commission VII, WG VII/5
}

KEY WORDS: Remote Sensing, Rice, mapping, MODIS, Multi Sensor, Vegetation Indices, Inter annual variation

\begin{abstract}
:
Rice is the main water-consuming crop planted in Egypt Delta. Constrained with the limited water resources, mapping rice is essential for any better water resources management. Xiao(2005) developed an algorithm for rice mapping by studying the dynamics of three vegetation indices the normalized difference vegetation index(NDVI), the Enhanced Vegetation Index(EVI) and the Land surface water index(LSWI). Rice main differentiating feature is being planted in flooded land. Thus moisture sensitive index like LSWI will temporally exceed the EVI or the NDVI signalling rice transplanting. Xiao(2005) utilized MODIS free satellite imagery $(500 \mathrm{~m}$ spatial resolution). However its coarse resolution combined with the Egyptian complex landscape raised the need for the algorithm modification. In this piece of work a low -cost rice mapping algorithm was developed. The multi resolution(MODIS $250 \mathrm{~m}$ red and near infrared bands) and (MODIS 500m -shortwave infrared and blue bands) were utilized. The arable land was mapped through the utilization of the NDVI and applying it on MODIS $250 \mathrm{~m}$ (fine spatial resolution) scenes. The MODIS fine temporal resolution (MOD09A1 product) was utilized to study the LSWI, NDVI and EVI dynamics throughout the rice planting season. The non-arable land from MODIS $250 \mathrm{~m}$ was then used to refine the rice area calculated from the MODIS $500 \mathrm{~m}$ imagery. The algorithm was applied on the Egypt delta region in years 2008, 2009, and 2010. The mapped rice areas were enhanced from the MODIS $250 \mathrm{~m}$ arable mapping module and the results of the algorithm were validated against annual areas reports. There was good agreement between the estimated areas from the algorithm and the reports. Inter annual variation in rice areas was successfully mapped. In addition, the rice area and probable transplanting dates conforms to local planting practices. The findings of this study indicate that the algorithm can be used for rice mapping on a timely and frequent manner.
\end{abstract}

\section{INTRODUCTION}

\subsection{Objectives}

The main objective of this research is developing low-cost rice mapping remote sensing based algorithm utilizing free satellite imagery, geographic information system (GIS) and field data.

\subsection{Definition of the problem}

Egypt share of water from river Nile is fixed with an annual amount of 55.5 billion $\mathrm{m} 3$. In addition, with the population increase the per capita share of water rapidly decreased from nearly $2000 \mathrm{~m} 3 /$ capita/year in 1959 to just $900 \mathrm{~m} 3 /$ capita/year in 2000 . Moreover, the problem is further complicated as it is predicted that the per capita share will be only 536 $\mathrm{m} 3 /$ capita/year by year 2025 (AbdElhai, 2002). FAO defines the water poverty line as $1000 \mathrm{~m} 3 / \mathrm{capita} /$ year which signals that Egypt is classified as having a water poverty problem. The agriculture sector is the main water consumer in Egypt with an amount representing $83 \%$ of the available (CAPMAS, 2013). . Rice is the most water-consuming crop planted in summer (Doss, 2001). Consequently, Rice is the most critical crop that should be mapped. Although accurate and timely information serve as the basis for any decision making process. Updated information about the vegetation area in Egypt and the rice fields planted is problematic. Every year the ministry of water resources and irrigation (MWRI) limits rice area to be planted in Egypt to 1.1 million feddan. This is to avail irrigation water to all agricultural land considering the limited water resources. In addition, this limit is related to the conveyance capacity of the irrigation network and its ability to satisfy the intense irrigation demands. Nevertheless, due to socioeconomic factors the farmers prefer to plant rice in their fields in violation of the MWRI regulations. Rice is the main water-consuming crop planted in the Delta. Thus rice mapping is essential for any water resources management improvement. The traditional methods like census and ground surveying are labour some, money and time consuming processes. On the other hand, remote sensing can provide a faster and updated mean for rice mapping. Mapping rice area can serve in building a spatial and temporal inventory of rice (where and when rice is planted). In addition, mapping rice area can be used in the determination of rice areas that are planted in violation of the MWRI regulations. An estimate of rice crop yield can be obtained from the rice area mapped. Knowing rice planting date for each rice area can help in the future planning of the delivery of the required irrigation water to rice areas especially in the most critical dates required.

\subsection{Motivation}

Identifying the cropland and crop types accurately on a large area scale with the traditional methods is uncertain. Remote

\footnotetext{
* Corresponding author. This is useful to know for communication with the appropriate person in cases with more than one author.
} 
sensing satellite images serve as a valuable source of data. Numerous studies since the seventies had shown that remote sensing is an ideal tool for vegetation mapping. The on-going research continues to enhance the mapping accuracy. Feature extraction plays a significant role in correctly interpreting and extracting valuable information from the images. Various types of satellite images that differ in their spatial, spectral and temporal characteristics can be used for vegetation mapping (Xie, 2008). Utilizing the technology of remote sensing is a practical and economical way to study the changes in the vegetation cover especially on large areas (Langely, 2001; Nordberg, 2003). Varying band combination and classification techniques affects the accuracy of portioning the space in the image to distinct classes. Cropping pattern is one of the important patterns to be identified and extracted accurately; to accomplish this task, feature extraction techniques are used. The spectral reflection of crops changes by crop type, phonology and health allowing it to be mapped and monitored by multispectral sensors. Rice mapping through remote sensing was conducted in several studies. Both radar and optical imagery were used for rice mapping in Turkey, Japan, Italy, China, Indonesia, and South East Asia. But due to the heterogeneous nature of the Egyptian cropping pattern, mapping rice in Egypt is a challenge. After reviewing the literature, no remote sensing based algorithm for rice mapping in Egypt that can utilize the imagery from the free domain and achieve high accuracy was found. Instead, the traditional method of rice areas reporting is doubtful. Accordingly developing a remote sensing based algorithm for rice mapping in Egypt will be of great importance; for better water resources management, planning and decision-making.

\subsection{Approach in General}

In order to develop an economic algorithm for rice mapping with high accuracy utilizing remote sensing and GIS, fine resolution imagery is used for arable area mapping. Frequent coarse resolution imagery is used for rice area mapping by examining the dynamics of vegetation and other remote sensing driven indices. The blending of fine resolution imagery arable area mapping and the coarse resolution imagery rice area mapping is applied. Annual rice area reports and knowledge of rice planting practices will be used for the validation of the rice mapping algorithm. The developed algorithm will be applied for rice area mapping in Egypt delta. The effect of arable area tuning will be calculated.

\subsection{Vegetation Indices}

The vegetation indices (VI) depend on the vegetation reflectance pattern where there is a sudden peak in the NIR reflectance compared to the Red wavelength reflectance. Combining the red and NIR wavelengths a variety of VI were developed. The three vegetation indices used in this research are NDVI, EVI and LSWI shown in equations (1), (2), (3) respectively.

NDVI $=($ NIR- Red $) /($ NIR + Red $)$

$\mathrm{EVI}=2.5 *(\mathrm{NIR}-\mathrm{RED} /(\mathrm{NIR}+6 * \mathrm{RED}-7.5 * \mathrm{BLUE}+$ 10000))

LSWI $=($ NIR- SWIR $) /($ NIR + SWIR $)$
Red=the red band $(620-670 \mathrm{~nm})$

Blue $=$ the blue band $(459-479 \mathrm{~nm})$

$1652 \mathrm{~nm})$

The NDVI ranges from -1 to 1 . Healthy vegetation NDVI value is in the range of $0.5-0.9$. While water bodies have very low or negative NDVI values. The enhanced vegetation index (EVI) is a modification of the NDVI to correct for some distortions caused by atmospheric interaction as well as the ground cover under vegetation. Another developed index that is sensitive to vegetation water content is the land surface water index (LSWI). Unlike NDVI, EVI which changes in response to vegetation greenness the LSWI changes in response to vegetation moisture.

\section{THE RICE MAPPING ALGORITHM}

\subsection{Rice mapping Algorithm}

In this research a rice-mapping algorithm for Egypt Delta will be developed. The freely available MODIS imagery $500 \mathrm{~m}$ (SWIR, and Blue bands) and the finer MODIS $250 \mathrm{~m}$ bands (NIR, Red bands) will be utilized. The MODIS Terra/Aqua Surface Reflectance 8-Day L3 Global 500 m (MOD09A1) product and 250m (MOD09Q1) were used. For each pixel, the best observation value in the 8-day record is selected based on high observation coverage, low view angle, absence of clouds or cloud shadow, and aerosol loading. The algorithm consists of two modules. The first is the arable land mapping module. Fig 1 shows a flowchart summarizing the steps carried out by the arable land mapping module to differentiate among arable and non-arable lands. This depends on the finer spatial resolution bands NIR and Red. The finer spatial resolution $250 \mathrm{~m}$ bands are used for the arable land mapping. This is achieved by first the proper selection of an image date that satisfies the following conditions. i. the agriculture land is completely vegetated. ii. Not in the rice planting season to minimize the potential of the misclassification of rice flooded lands as non-vegetative areas. The NDVI is calculated for that image. A threshold for differentiating between arable and non-arable lands is determined; this is through examining the NDVI values for known arable and non-arable land samples randomly distributed in the whole mapped area. For this classification, high or medium resolution imageries can be used even if their date is not in the rice-plantation period or even the same year when rice mapping is carried out. 


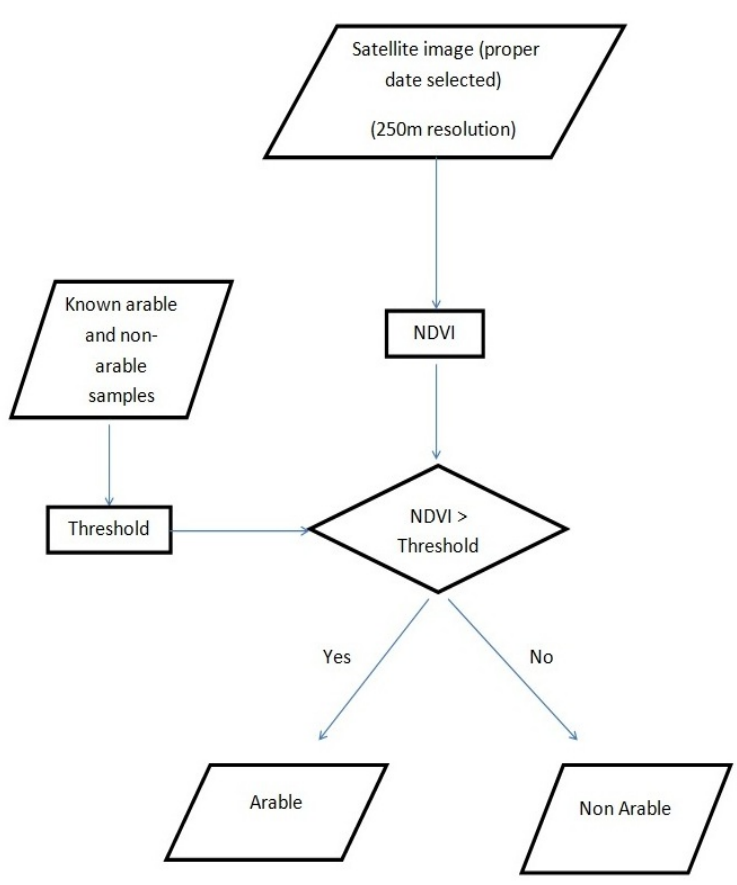

Figure 1. Flowchart showing arable areas mapping module

While Fig 2 shows the steps for the vegetation indices dynamics module. This is for examining the LSWI, NDVI and EVI dynamics and rice mapping. The basic assumption is that LSWI will temporally exceed NDVI and/or EVI during the rice flooding. The fine temporal $500 \mathrm{~m}$ images are used for the NDVI, EVI, and LSWI calculations. The combination between the $250 \mathrm{~m}$ and $500 \mathrm{~m}$ MODIS imagery in the algorithm will benefit from MODIS imagery fine temporal resolution and minimizing its mixed pixel shortcoming with the usage of $250 \mathrm{~m}$ fine spatial resolution.

\subsubsection{Cloud Contamination Correction}

Although MOD09A1 records pixels with low cloud coverage, there are still pixels contaminated with clouds. These pixels could be misclassified as rice. This is because it will have a LSWI greater than EVI or NDVI. In order to mitigate this misclassification potential, a model was built to check for clouds. Clouds reflectance in the blue band is typically greater than 0.2 thus a simple condition of testing the blue band reflectance was used to mask the cloudy pixels (Blue reflectance $>0.2$ therefore clouds).

\subsubsection{Permanent Water and Fish Farms Correction}

Following the rice mapping assumption, permanent water bodies or fish farms may be classified as rice. In order to avoid this misclassification potential the permanent lakes and water bodies are masked from the MODIS imagery by their shape files. In addition, if a pixel satisfies the criteria of LSWI $+\Delta>$ $\mathrm{NDVI}$ or LSWI $+\Delta>\mathrm{EVI}$ in more than 6 dates this signals that this pixel is not rice but rather water. In a rice field the vegetation cover starts to grow and will cover the water in the field in nearly forty day duration of the planting season.

\subsubsection{Rice Planting Calendar Correction}

Another condition is applied if the date of satisfying the rice planting detection criteria takes place after end of August then the pixel will be classified as water as this is not possible according to the rice-planting calendar in Egypt delta.

\subsubsection{Rice area tuning}

The drawback of the MODIS imagery is its coarse resolution. In order to refine the rice area detected by MODIS imagery, the rice mapping algorithm combines mapping of arable land obtained by higher resolution $250 \mathrm{~m}$ imagery which can be used to differentiate between vegetation and non-vegetation areas.

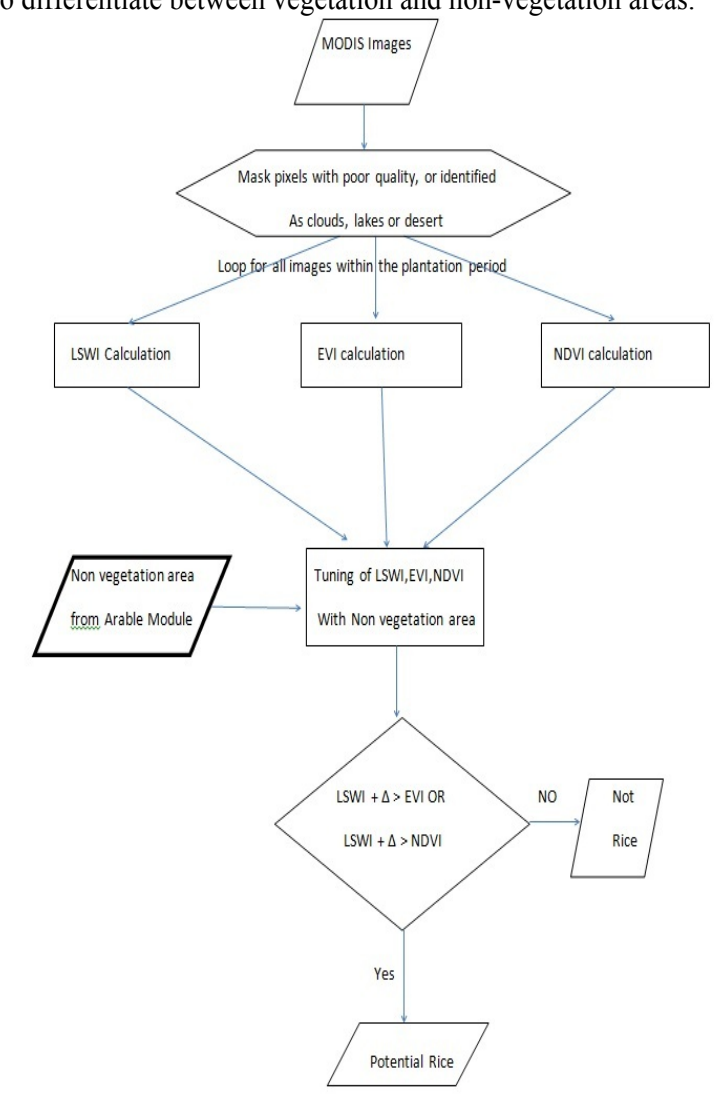

Figure 2. Flowchart showing rice mapping algorithm

\section{THE APPLICATION OF THE RICE MAPPING ALGORITHM ON THE DELTA REGION OF EGYPT}

\subsection{Study Area}

Rice is mainly planted in Egypt delta region. The delta area is about $30,000 \mathrm{~km} 2$. The delta region is bounded in the north with the Mediterranean Sea, in the west with the western desert, in the east with the eastern desert and in the south with the Egyptian capital Cairo. It covers the area south-north from $30^{\circ}$ $4^{\prime} \mathrm{N}$ to $31^{\circ} 36^{\prime} \mathrm{N}$ and east-west from $32^{\circ} 12^{\prime} \mathrm{E}$ to $29^{\circ} 25^{\prime} \mathrm{E}$. 


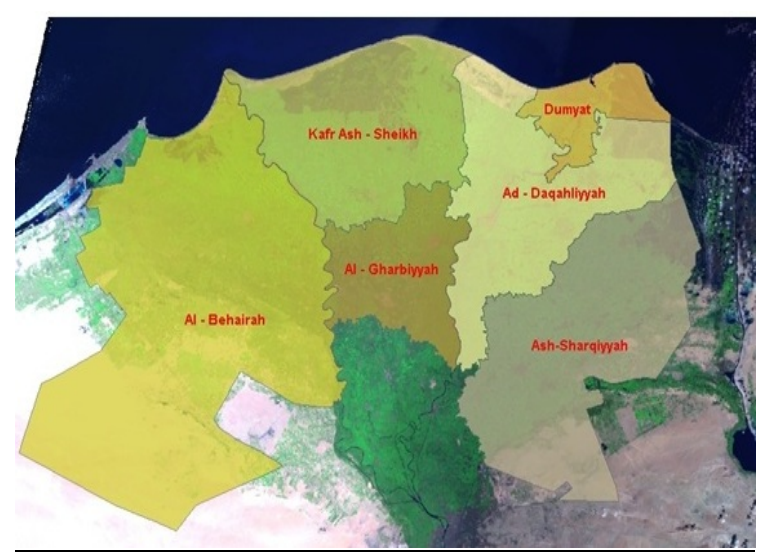

Figure 3. Egypt Delta Region and rice planting governorates

\subsection{Data and Methods}

The imagery used for the rice mapping algorithm were the MODIS Terra/Aqua Surface Reflectance 8-Day L3 Global 500 $\mathrm{m}$ (MOD09A1) product and the MODIS Terra/Aqua Surface Reflectance 8-Day L3 Global $250 \mathrm{~m}$ (MOD09Q1) product. The tile of these products that covers the delta region is h20v5. The MOD09Q1and MOD09A1 images covering the delta region were downloaded from http://reverb.echo.nasa.gov/reverb/. By examining the rice planting calendar in Egypt the MOD09A1imagery from 15-April till 9- November in years 2008, 2009 and 2010 were obtained .The delta region area of interest was used to clip the images. Each image is then projected to the UTM zone 36 with the WGS84 datum to have the same projection with the available main lakes and desert areas, Nile River, and governorates boundaries GIS shape files. The shape files were superimposed on the MODIS imagery to mask their areas out. These images were utilized for rice mapping by arable land mapping and analysing the LSWI, NDVI, EVI dynamics in the various governorates of the delta region of Egypt following the procedure outlined in Figure 1 and 2.

\subsection{The application of the arable land mapping module}

The appropriate MOD09Q1image date for the arable mapping module is selected. From the local knowledge the period in the winter season from 15 January to 15 February will have the arable land completely vegetated and there is no rice planted in the winter season thus satisfying both conditions of the agriculture land is being completely vegetated and not in the rice planting season to minimize the potential of the misclassification of rice flooded lands as non-vegetative areas. The fine spatial resolution $250 \mathrm{~m}$ images (NIR, Red bands) dated 2-2-2009 were used. The NDVI is calculated for the image. The NDVI values of many samples of known arable and non-arable land was examined. It was found that the appropriate NDVI threshold value to differentiate between arable and nonarable is 0.35 .This value is used in the arable land mapping module which was applied to map the Delta arable land. Fig 4 shows the delta arable land after running the arable land mapping module. The delta arable land was found to be 5.2 million feddans.

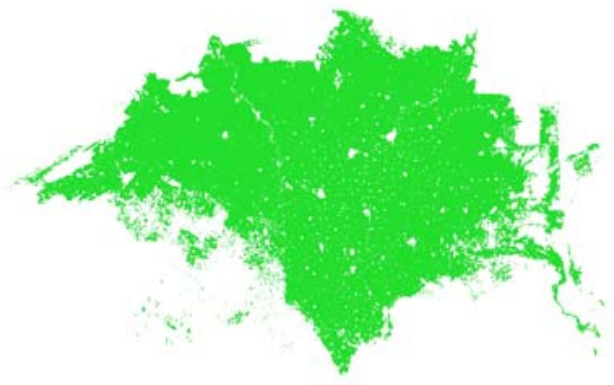

Figure 4. Egypt Delta Arable land

\subsection{The Analysis of LSWI, NDVI, and EVI Dynamics for Rice Mapping}

The MODIS (MOD09A1) product 500m SWIR, NIR, Red, and Blue bands were used for the EVI, LSWI calculations as shown in equations (2), and (3) respectively. The main differentiating feature is that rice is planted on flooded land. The basic assumption is that a moisture sensitive index like the LSWI will temporally exceed greenness sensitive index like the NDVI or EVI thus signaling rice transplanting. Fig 5 shows the NDVI, EVI and LSWI dynamics through the whole rice planting season for a known rice field in the delta.

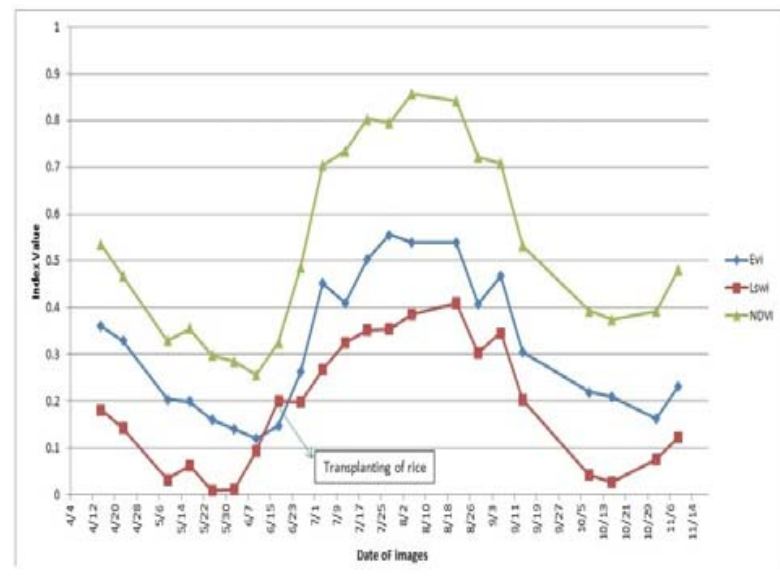

Figure 5. LSWI, NDVI and EVI indices for a rice field during the planting season

\subsection{Results and Discussion}

Table 1 shows the results of applying the rice mapping algorithm on the Delta images in the years 2008, 2009, and 2010.

\begin{tabular}{|l|r|r|r|}
\hline & \multicolumn{2}{|c|}{ Rice Area } & \\
\hline & Without_arable_mask & Masked_with_arable_land & Reduction \\
\hline Year 2008 & 2711800 & 2324900 & $14 \%$ \\
\hline Year 2009 & 2327600 & 1968000 & $15 \%$ \\
\hline Year 2010 & 1613700 & 1353200 & $16 \%$ \\
\hline
\end{tabular}

Table 1. Egypt Delta Rice Area in years 2008, 2009, and 2010

The application of the rice mapping algorithm in years 2008, 2009 and 2010 showed that tuning the rice area with the arable land mapping module corrected the rice area in the delta region by 14,15 and $16 \%$ respectively. Fig 6 shows the output of the algorithm application on the delta region in 
2009.

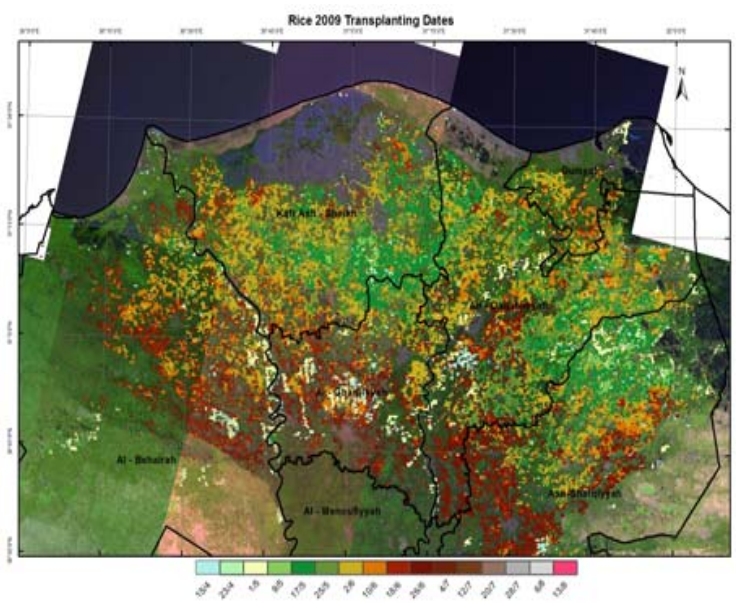

Figure 6. Output of the Rice area mapping Algorithm applied in 2009 for the Delta Region (Rice areas and transplanting dates)

\section{VALIDATION}

Due to resources limitations a complete field samples was not obtainable. But comparing the algorithm results with the national rice area statistics and figures produced by the Egyptian ministry of Agriculture and land Reclamation revealed that the algorithm correctly mapped the inter annual variation in the rice areas in these three years. Table 2 shows the comparison

\begin{tabular}{|l|r|rr|}
\hline & \multicolumn{3}{|c|}{ Rice Area } \\
& Ministry of agriclture statistics & Rice Algorithm & \% Difference \\
\hline Year 2008 & 2067986 & 2324900 & $12 \%$ \\
\hline Year 2009 & 1712435 & 1968000 & $15 \%$ \\
\hline Year 2010 & 1228249 & 1353200 & $10 \%$ \\
\hline
\end{tabular}

Although there is a discrepancy of 10 to $15 \%$ in the rice areas from the algorithm output and the official figures but the inter annual variation is correctly mapped. Not to mention that the official figures depend on traditional methods like census and ground surveying lowering the confidence in the figures within large areas like the Egyptian Delta. Another thing is worth mentioning is that the algorithm depends on free satellite imagery reflecting the very low-cost advantage of using and applying it. Fig 6 also shows that rice transplanting dates in the northern part of the delta area is earlier than those of the southern parts. In addition, almost no rice is planted in Menofiya governorate and these findings conform to local experience and knowledge.

\section{CONCOLUSIONS}

This research findings show that an economic remote sensing based rice mapping algorithm was developed using MODIS (Fine temporal resolution) free imagery with $500 \mathrm{~m}$ resolution. This was achieved by studying the relation between the land surface water index (LSWI), normalized difference vegetation index (NDVI), and enhanced vegetation index (EVI) indices dynamics throughout the rice planting season. The devised algorithm can capture the most differentiating feature of rice (being flooded in the transplanting period). Rice can be mapped following the criteria of LSWI is temporarily greater than EVI or NDVI in the period of rice transplanting (LSWI > EVI or LSWI > NDVI). Arable land mapping module was developed. The MODIS $250 \mathrm{~m}$ (Fine spatial resolution) imagery was used for mapping arable land. This was achieved by studying the
NDVI for known arable and non-arable land thus enabling the determination of an NDVI threshold for arable and non-arable land differentiation. The blending of arable land mapping module with fine spatial resolution imagery can enhance the accuracy of rice mapping from MODIS $500 \mathrm{~m}$ imagery. This was done by masking out non-vegetation areas within each MODIS pixel that was mapped from MODIS $250 \mathrm{~m}$ imagery and the arable land mapping module. This decreases the major shortcoming of the mixed pixel dilemma occurring with MODIS especially in heterogeneous areas. The spatial distribution of rice planted areas and rice transplanting dates was identified with the developed mapping algorithm.

The application of the rice-mapping algorithm to Egypt's delta was carried out for 2008, 2009 and 2010. Inter annual variation in the rice areas was correctly mapped. A good agreement between the results of the algorithm to the official field surveyed rice area figures was achieved. In addition the results and rice transplanting dates conformed to local rice planting practices and knowledge.

\section{References:}

Abd-El-Hai M.,(2002).Rural Non-farm Employment Workshop. Current and emerging issues for economic analysis and policy research CUREMIS II NENA. FAO.INP.

CAPMAS.2013, Egypt in Figures, water resources, Central Agency for Public Mobilization And Statistics CAPMAS report 2013

Doss M., Milne G., (2001). Water as an Economic good: an approach to the Egyptian economy, the Beijer Workshop on Property Rights Structures and Environmental Resource Management, Egypt, March 2001

Langley SK, Cheshire HM, Humes KS (2001). .A comparison of single date and multi temporal satellite image classifications in a semi-arid grassland. Journal of Arid Environment 49:40111

Nordberg ML, Evertson J (2003). Vegetation index differencing and linear regression for change detection in a Swedish mountain range using Landsat TM and ETM+ imagery. Land Degradation \& Development 16:139-149.

Xiao X., (2005). Mapping paddy rice agriculture in southern China using multi-temporal MODIS images, Remote Sensing of Environment 95, 480-492

Xie Y., ShaZ., Yu M., (2008), Remote sensing imagery in vegetation mapping: a review, Journal of plant ecology, vol 1, no 1 